\title{
Group Investigation Learning Implementation and EAOAT-Based Assessement on Profession Education Subject
}

\author{
Krisna Merdekawati ${ }^{a, *}$ \\ ${ }^{a}$ Department of Chemistry Education, Islamic University of Indonesia \\ *Corresponding author: krisna.merdekawati@uii.ac.id
}

\begin{abstract}
Profession Education subject has wide coverage lecture material and tend to be regarded as a theoretical matter. Profession Education conventionally, students will only examine theoretically and less meets the subject goals. Evaluation shows that it needs improvement efforts from material aspects, strategies, and assessment systems in Profession Education lectures. The study focused on the description of the implementation and effect of group investigation (GI) in Professions Education subject, a description of EAOAT-based assessment implementation. Subjects of this study were students of Chemistry Education Department, Islamic University of Indonesia who took Profession Education subject in the academic year 2016/2017. Lectures conducted with the collaboration of lecturers and expert lecturers from National University of Malaysia. The research instruments include course outline, hand outs, diagnostic tests, project assessment, cognitive assessment, self-assessment, student satisfaction questionnaires, and expert lecturer's assessment questionnaire. Lectures conducted in accordance with the stages in the Gl, namely: identification of topics, planning investigations, execution of investigations, preparation of the final report, presentation of the final report, an evaluation of progress. Oriented learning outcomes should ideally use a rating system that can give a continuous process and performance. With EAOAT-based assessment, teachers can determine the difficulties and competencies that have not reached by the students. Lecturers can further specify corrective measures in learning to allow students to achieve competence expected. Data research shows that GI learning and EAOAT-based learning has a positive impact. The final grade point average of students was 79.2. The average score of student satisfaction was 92.5. The expert lecturer's assessment scores were 95.8. From self assessment showed that students understand the lecture material and the interest in the teacher profession was increased after the lecture.
\end{abstract}

Keywords: group investigation, EAOAT assessment, Profession Education

\section{INTRODUCTION}

Teacher competence is an important issue in development of education and is the focus of in many universities, especially those that run pre-service teachers academically [1-4]. One of the learning outcomes that should be owned by Chemistry Education graduates as a candidate for chemistry educators (teachers) is master chemistry concepts, pedagogy, learner's improvement, the school curriculum and knowledge relevant to chemistry education. Profession Education subject is one of the subjects that was organized to support the learning outcomes. This subject is given in semester 5 with a weight of 2 credits. Profession Education examines the professional position of teachers, teacher competence, professional and career development, performance assessment, ethics and professional code of ethics, professional organizations, expanding the role of the teacher. Lecture material scope is wide and tends to be regarded as a theoretical matter. The learning goals of Profession Education subject are: 1) understand the teacher position as a profession, 2) understand the competencies, rights, and teacher obligations, 3) understand the concept of teacher professional development. The lecture learning goals support the learning achievements of graduates in the mastery of knowledge relevant to chemistry education.

For students of Chemistry Education Department, be a teacher is not a primary choice. It needs more effort to introduce and attract students to the Profession Education subject. Profession Education lectures conventionally defined as students will only assess theoretically, less meets the subject goals. Cooperative learning is one of the important strategies in educational practice [5]. One model in a 
cooperative learning that can be a learning strategy alternative used in the subject of Profession Education is a group investigation (GI). Gl appropriately applied in the Profession Education subject because it is relatively easy and suitable for subjects that can be divided into topics of investigation.

In addition to selecting the right model, the content of Professions Education lectures must comply with the development, expectations and demands of the people in the teaching profession. Issues and contemporary aspects need to be material in Profession Education lectures. The enforcement of ASEAN Economic Community (AEC) is to be a challenge for Chemistry Education Department to equip and prepare students to be able to compete at least at the regional level ASEAN. Students need to understand the concepts of the education profession, not only refer to the applicable laws and regulations in Indonesia, but also at regional and global level. The current direction of educational field development is the development of $21^{\text {st }}$ century skills. Students need to be equipped on the profile of the $21^{\text {st }}$ century teacher. The capacity of lecturers on such materials need to be improved, lectures by professors of foreign experts is indispensable. With the involvement of foreign expert lecturers in teaching and learning activities, lecturer and students can broaden the concepts related to the teaching profession at the ASEAN level and profile of the 21st century teachers. The expectation is with collaborative lectures, GI learning model implementation can support the achievement of learning subjects and improve student interest in the teaching profession. Students are more open-minded to see teacher opportunities in the ASEAN region in the $21^{\text {st }}$ century. Students also facilitated to deepen the knowledge about the teaching profession through an investigation carried out in groups.

Materials, instructional strategies, and assessment are a system that needs to be aligned in the implementation of qualified lectures. In accordance with the regulation, Number 44 Year 2015 on National Standards of Higher Education, the principle of student learning processes assessment and outcomes include educational principles, authentic, objective, accountable, and transparent (EAOAT). Currently, lecturers often rely on assessment through summative test and tasks. Summative test does not accommodate the implementation of mastery learning. Competence-oriented learning or achievement was ideally used a scoring system that can give a continuous process and performance. According to the principles EAOAT, assessment is not only intended to measure student learning outcomes. Assessment was also developed to improve planning and learning strategies. EAOAT-based assessment not only oriented to measure learning outcomes but also can diagnose student's difficulties. With EAOAT-based assessment, lecturer can find out the difficulties and competencies that have not reached by the students. Lecturers can further specify corrective measures in learning to allow students to achieve the expected competencies. This matter cannot be done simply by using summative tests. EAOAT-based assessment system development can support the achievement of learning outcomes for students (graduates). This study applies GI in collaborative lectures with Faculty of Education, National University of Malaysia. The study focused on the description of the application and effect of $\mathrm{Gl}$ in lectures, the description of the application of a EAOAT-based assessment.

\section{LITERATURE REVIEW}

GI was developed by Sharan at the University of Tel Aviv, which consists of four basic components, namely investigation, interaction, interpretation, and intrinsic motivation [6]. Gl is one model of learning that can develop interpersonal skills, problem solving and learning skills [7]. In the model of GI, students are grouped heterogeneously. Students choose their own topics or material to be studied. The groups formulate investigation and the division of labor to discuss the concepts of investigations that have been formulated. Lecturers act as a source of learning. The work progress of the group was reported as a class discussion topic. In class discussion, students prioritize higher order thinking. The evaluation of activities is conducted through the accumulation of individual work during the investigation. The important concept in GI learning prioritizes learning by doing, give priority to the interest of students, treat students as personal responsible. Through the group investigation, students can be challenged to complete tasks based on the selected topic. Gl was positioned students as individuals who are able to work in a responsible manner. Implementation of $\mathrm{Gl}$ is expected to support the learning outcomes of education profession subject and improve student interest. Interests can be grown as students facilitated the task corresponding interest in the topic. Students actively seek sources of study, and communicate the results of the investigation. Through learning by doing, students are expected to find and become interested in the concepts of the teaching profession. It is difficult to obtain through conventional lectures. The students only receive materials from lecturer, no challenge and an opportunity to review the material independently and responsibly. 
There are 6 stages in the Gl learning model [8]: 1) the identification of topics, at this stage group setting was being conducted. Lecturers presented a series of material or problem. Students are asked to write a paper on the materials. Students identify and select materials based on interest, students are grouped based on their interest in the material. Lecturer ensures heterogeneous group formation. 2) Planning the investigation, members of the group focus on the material that has been selected, determine the learning resources that can be used to learn the material, and how the completion of the task. 3) Implementation of the investigation, each group carries out a work plan for accomplishing the task. Students gather information, analyze data, and make conclusions. This stage can facilitate students to exchange ideas, clarify, and synthesize idea. 4) Preparation of the final report, this stage is a transition stage of data collection, clarifications to the reporting results of the investigation stage. 5) Presentation of the final report, each group prepares to present their final report which is the result of an investigation carried out. 6) Evaluation of the achievement, the evaluation is done collaboratively between lecturer and students. Lecturer evaluate what students learn, including if there is material that has not been thoroughly discussed, conclusion. Students evaluate each other on the tasks and presentations made, the effectiveness of learning experiences gained. The implementation of Gl can provide a positive impact to students. GI facilitates the use of inquiry skills, so that it gave positive impact on the ability to find information. GI promotes academic achievement, motivation, thinking skills, self-efficacy, conceptual knowledge, process skills, writing skills $[5-7,9,10]$.

According to the regulation in Indonesia, the principle of the assessment include educational principles, authentic, objective, accountable, and transparent which is done in integration. Educative principle is an assessment that can motivate students to be able to improve planning and strategies, achieve the learning outcomes of graduates. That is, the assessments are not solely measure learning outcomes. Assessments are also able to provide a description of the problems faced by students in achieving the learning outcomes. Assessment data can be used by lecturer to determine aspects or material that has not mastered by students, so it can be repaired learning. Authentic principle is an assessment oriented continuous learning process and the learning outcomes that reflect the ability of students during the learning process. Assessments are not merely assessing the results, but it is a continuous process. Assessments should be adapted to the learning experience accepted by the students. The objective principle is an assessment based on standards agreed between lecturers and students, and free from the influence of subjectivity assessors and assessed. Subjectivity can be minimized by making the assessment rubric. The principle of accountability is the assessment carried out in accordance with clear procedures and criteria, agreed upon at the beginning of lectures, and understood by students. The principle of transparency is an assessment that is accessible by all stakeholders.

\section{RESEARCH METHODS}

The study used a descriptive approach. The study focused on the description of the application and effect of $\mathrm{Gl}$ in lectures Professions Education, a description of the application of EAOAT-based assessment. Subjects were students of Chemistry Education Department, Islamic University of Indonesia who took Profession Education subject in the academic year 2016/2017. Lectures conducted with the collaboration of expert lecturers and professors from the Department of Teaching and Learning Innovation Universiti Kebangsaan Malaysia.

Stages in the research activities include: 1) the development of research instruments, 2) implementation, 3) data collection and analysis. The develop instrument consists of implementation of research instruments and data collection instruments (assessment). Implementation of research instruments includes the course outline and hand out. Course outline was structured based on GI syntax. The hand out formulation was done by lecturers and professors of foreign experts, in accordance with the distribution of the materials. Hand outs in the printed version and android. Hand out the android version can be downloaded via the link http://bit.ly/download_pk_app.

Assessment instruments arranged on indicators set. The development of assessment instruments refers to the Indonesian Regulation which it is EOOAT-based. Validation of construct instruments has been carried out by an evaluation of education expert and has been fixed in accordance with expert input. Assessment instruments such as diagnostic testing, project assessment, cognitive assessment, selfassessment, student satisfaction questionnaires, and expert lecturers assessment questionnaire.

The diagnostic test was developed by 2 instruments. Diagnostic tests used by lecturer to determine whether there is the difficulty of student learning and achievement of student learning that has not mastered yet. Students can use the results of the diagnostic test assessment to improve learning, explore 
related content on the achievements that have not been reached. The first diagnostic tests related to the achievement of understanding teacher position as a profession and understand the competencies, rights and obligations of teachers. The second diagnostic tests related to the achievement concept of teacher professional development understanding. The diagnostic test is test with a short field.

Assessment of the project consists of three aspects; the assessment of planning, implementation, and products. In order the project can be an objective assessment; it made an assessment rubric that can be used as a reference in the assessment. Assessment rubrics describe the achievements of each indicator and a score reached. Cognitive tests at the time are developed based on the learning outcomes of Professional Education subject. Self assessment developed in the form of enclosed questionnaire with the category of yes and no answers. Student satisfaction questionnaire developed to assess aspects: 1) the quality of lecturer, 2) quality foreign expert lecturers, 3) the effectiveness of GI, 4) the effectiveness of collaborative learning, 5) the quality of handouts. Expert lecturer's assessment questionnaire developed to assess quality aspects: 1) the instructional design, 2) implementation of learning, 3) evaluation of learning, 4) the lecture material. Data collection performed during the lectures take place. Lectures conducted 14 times using a model of GI. For the 10-14 meeting was taught by lecturers of foreign experts. The data were analyzed and described.

\section{RESULTS AND DISCUSSION}

Lecture has already been held 14 meetings. Lecture at the meeting 1-9 held with GI models. GI appropriately used for the material that is reading and can be divided into smaller topics such as the Education Profession subject. GI Syntax is 1) the identification of topics, 2) investigation planning, 3) implementation of the investigation, 4) the preparation of the final report, 5) presentation of the final report 6) evaluation of progress. At the first meeting lecturer explained about the purpose of the lecture, a model of learning, and assessment systems. Lecturer described the syntax GI models and projects to complete. Projects such as the book contain topics in the education profession. Lecturer identifies topics to be studied and students are grouped according to their interest in the topic. Lecturer ensures heterogeneous group formation. Each group consists of 5-6 people (subject identification stage). Furthermore, at the first meeting, the student is guided by lecturers to plan the completion of tasks and specify the time of completion. Lecturers provide the material in outline, deepening of the material is done through a given task. Lecturers give direction to students to bring appropriate learning resources based on selected topics started the second meeting (the planning stage of the investigation).

Starting the second meeting, the lecture begins with an introduction of material from the lecturer followed by an investigation carried out group. Investigations carried out through learning resources that can be accessed in the classroom. Observations show that the students actively in group discussions, access to learning resources outside lecturers, such as books, legislation, material from the internet. When encountering a new concept that has not been understood, active student asked the lecturer (implementation phase of the investigation). After the investigation, the students worked together to prepare a report or task given by lecturers (final report preparation stage). According to the agreement, presentation of the results of the investigation carried out at the meeting of 5,6 and 8,9 . On average at each meeting of the presentation, there are two groups that reported the results of investigation. Each group presented a topic of their choice. Learning process has been dynamic. Students tend to actively ask the group presentation (stage presentation of final report). Each meeting, at the end of the course lecturers conducted evaluation. Lecturer evaluate to what students learn, including if there is material that has not been thoroughly discussed and a conclusion. Students evaluate each other on the tasks and presentations made (evaluation stage).

All tasks created by the group then collected and compiled in a book as a final product. The chosen topics by student to be assignment is the certification of teachers, teacher performance assessment, professional organization of teachers, and the teachers' code of ethics, expanding the role of the teacher, the principal, vice principal, head of the laboratory, the head of the library, the headmaster, the school supervisor, counseling and guidance. The book which being student's tasks (project) has been arranged. The average value of projects undertaken by students is 75 . Aspects of assessment have not been up to the presentation aspects. Students still less master presentation skills. A record for lecturer is to sharpen the communication skills of students.

In the meeting 10-14, lectures conducted collaboratively with expert lecturers. The involvement of foreign experts is intended to broaden students. With the involvement of foreign experts lecturers in teaching and learning activities, lecturer and students can broaden the concepts related to the teaching 
profession at the ASEAN level. Here are the materials presented by expert lecturers: teacher's opportunities and challenges in AEC era, duties and obligations of teachers in the ASEAN region, ethics of teachers in the ASEAN region, the $21^{\text {st }}$ century skills of teachers, teachers' professional development and career. In general, material which being tasks from expert lecturer has been delivered. Experts lecturer involved in the planning, implementation, and evaluation. Specialist lecturer assist lecturer in designing materials related to the professionalism of teachers in ASEAN, prepare handouts; provide inputs to the valuation used. Expert lecturer also provides an assessment of the quality of lectures related Professions Education. Expert lecturers fill out questionnaires to assess the quality of planning, implementation, evaluation, and course materials. All aspects assessed by expert lecturers were good. Questionnaire score from expert lecturer at 95.8.

From the assessment aspect, the assessment carried out by the EAOAT-based. EAOAT-based assessment not only oriented to measure learning outcomes but also can function to diagnose the difficulties of students. Educative principle is an assessment that can motivate students to be able to improve planning and strategies, achieve the learning outcomes. In the implementation of the principle of educational, lecturer constantly motivate students to achieve the learning goals. Lecturer develops diagnostic tests to implement the educational principle. The diagnostic test is given 2 times, first to understand the learning goals teacher position as a profession and understand the competencies, rights, obligations of teacher. The second diagnostic test for the learning goals is to understand the concept of teacher professional development. From diagnostic tests, lecturer can determine which aspects of weakness and provide follow-up in the form of review material, motivation, and strategies suggestions. For example, to understand the achievements of teacher competence, 22 out of 35 students do not understand the teacher's competence. Data diagnostic test used to re-review the material associated with the achievements that have not been reached. The diagnostic test is very effective to help lecturer and students in achieving the learning objectives. Lecturers also provide feedback from any assessment given and provide motivation, project progress assessment data, and lecturer observation data.

Authentic principle is an assessment oriented continuous learning process and the learning outcomes that reflect the ability of students during the learning process. Assessments are not merely assessing the results, but it is a continuous process. Assessments should be tailored to the learning experience of students. Assessment conducted by lecturers is processes and results. Lecturers assess students through observation, project assessment, cognitive tests, and self-assessment. Developed assessment projects apply the principles of authentic, all aspects of the process and the results assessed, which includes aspects of planning, implementation, and final products.

The objective principle is an assessment based on standards and free from the influence of subjectivity assessors and assessed. Lecturer develops an assessment rubric to implement the objective principle. An assessment rubric can minimize the emergence of subjectivity in the assessment. Developed assessment instrument has been equipped with the assessment rubric.

The principle of accountability is the assessment carried out in accordance with clear procedures and criteria, agreed at the beginning of lectures, and understood by students. The scoring system applied has been agreed between lecturers and students at the first meeting of lectures. The principle of transparency is an assessment that is accessible by all stakeholders. In the process of implementation, students have the freedom to see all the results of the assessment aspects and lecturer's assessment.

Assessment mechanism consists of: 1) develop, deliver, agree on steps, techniques, instruments, criteria, indicators, and the weight of assessment between the assessor and the assessed based on lesson plans, 2) carry out the assessment process according to the stage, techniques, instruments, criteria, indicators and weight of assessment for the principle of assessment, 3) provide feedback and the opportunity to question the assessment results to students, 4) document the assessment process and the learning outcomes of students accountable and transparent.

Evaluation of the program focused on evaluating the process and outcomes of learning. Assessment of learning outcomes includes project assessment, cognitive assessment, and self-assessment. The quality assessment of the learning process use lecturer teaching performance, student satisfaction questionnaires, expert lecturer questionnaire, and observation data. Evaluation generally indicates that the student has reached the learning goals. Students have been able to understand the position of teachers as a profession, to understand the competencies, rights, obligations of teachers, understand the concept of teacher professional development.

GI learning, collaborative lectures, EAOAT-based assessment contribute positively and directly to the achievement of the learning goals. Gl facilitate students to perform tasks corresponding interest in the 
topic, students actively seek sources of study, and communicate the results of the investigation. Through learning by doing, students can find the concepts of the teaching profession. In addition, GI also train students to work in a team. It is very good for sharpening the students' social skills, such as communication skills; respecting the opinion of friends, and working together which it is difficult to obtain through conventional lectures; the students only receive materials from lecturer, no challenge and an opportunity to review the material independently and responsibly, student tend to be bored. GI implementations according to student assessment are easy and fun to apply. Students are required to be active for searching learning resources to create presentation materials on the topic of their choosing. The learning process takes place relatively dynamic and students relatively more active.

The involvement of experts in real contributes to the achievement of the learning goals. Insight of students about the professionalism of teachers in ASEAN was increased by the presence of expert lecturers. It supports the learning goals understand the professional development of teachers. Besides, the involvement of expert lecturers increases student interest in the teaching profession. One of the questions in the self assessment is either increased or not the interest of students in the teaching profession after a collaborative lecture. The response of students, all students answered that the interest was increased. Although the law in Indonesia is increasing the workload of teachers, but the students see promising opportunities related to employment of teachers in the era of AEC. In the future, the material of expert lecturers need to be the subject matter discussed in the subject of Professional Education.

There are several factors that are a challenge for lecturer support when teaching Education profession subject. Meanwhile, the teaching profession has not become the primary choice for some students, and a comprehensive range of material tend to be considered theoretical, government policies relating to teachers tend to incriminate the task of teachers. If the lectures is done conventionally, it can be predicted in student interest in the teaching profession will be decreased. Material about the professionalism of teachers in ASEAN can provide positive aspects of student interest. The materials are important to include in the subject matter of Professional Education. So that students are open-minded about job opportunities in the era AEC.

EAOAT-based assessment effectively helps students. Lecturers provide feedback to the assessment, students can identify the learning goals yet secured. Assessment is not only the product but also the process, assessing all aspects of learning (authentic). Assessment should be transparent and objective so that students do not feel disadvantaged. The implementation of diagnostic tests provides an overview to the teachers about the student's difficulties to achieve the learning goals. Data from midterm and final test indicates that the student has the learning goals. The average value of midterm and final test students respectively is 80.9 and 83.4 . In the diagnostic tests performed, $62.9 \%$ of students known have difficulties in achieving the learning goals. Lecturer identifies topics related to the difficulty of students, provide motivation, and reviewing. This had a positive impact. Students can work on final test better than diagnostic tests. The implementations of GI according to student assessment are easy and fun to apply.

Evaluation quality of the implementation process of research generally shows good results. Lecturer teaching performance value in the subject of Professional Education was 3.87. Students give a good assessment. The average score of student assessment questionnaire was 92.5. Lecturer experts give lectures on the aspects of planning, materials, instructional strategies, and evaluation. Expert lecturer's assessment questionnaire score of 95.8. Lecturer of Education Professions experts assess lectures include materials that fit the needs of the working world. The assessment system used to assess aspects of the student completely. Learning strategies are used quite well. Lecturer experts suggest the integration of the e-learning system. Lecturers need to do is e-learning lectures in several meetings. It is intended to familiarize students with the utilization of IT in learning. Summary of research data can be seen in Table 1.

TABLE 1. Research data summary

\begin{tabular}{clc}
\hline No & \multicolumn{1}{c}{ Aspect } & Performance \\
\hline 1 & Students' final grade & Grade $\geq B=100 \%$ the average of final score \\
& & 79.2 \\
2 & The average score of student satisfaction & 92.5 \\
3 & $\begin{array}{l}\text { Score of international partners toward } \\
\text { process quality and the range of material }\end{array}$ & 95.8 \\
4 & Lecturer performance grade & 3.87
\end{tabular}




\section{CONCLUSION}

Profession Education lectures are conducted in accordance with the syntax in the GI, namely: 1) the identification of topics, Lecturer identify topics to be studied and students are grouped according to their interest in the topic. Lecturer ensure heterogeneous group formation, 2) planning the investigation, the students focus on the material that has been selected, determine the learning resources that can be used to learn the material, and how the completion of the task. Students are guided by lecturers to plan completion of the project, determine the time of collection and presentation, 3) implementation of the investigation, each group carry out the work plan of the group to complete the task, 4) preparation of the final report, this stage is a transition phase of data collection. Clarification to the stage of reporting the results of the investigation, 5) presentation of the final report, each group prepare to present their final report which is the result of an investigation carried out. 6) Evaluation of progress, the evaluation is done collaboratively between lecturers and students. Lecturer evaluate to what students learn, including if there is material that has not been thoroughly discussed and concluded. Students evaluate each other on the tasks and presentations carried out.GI facilitate students to perform tasks corresponding interest in the topic, students are actively seeking sources of study, and communicate the results of the investigation. Through learning by doing, students can find the concepts of the teaching profession. In addition GI also train students to work in a team. It is very good for sharpening the students' social skills. According to the assessment of students, Gl assist students in understanding the lectures, easy, and fun are applied.

The involvement of experts in real can contribute to the achievement of the learning goals. Insight of students about the professionalism of teachers in ASEAN was increased by the presence of expert lecturers. It supports the learning goals understand the professional development of teachers. Besides, the involvement of expert lecturers can increase student interest in the teaching profession. In the future, the material of expert lecturers need to be the subject matter discussed in the subject of Professional Education.

EAOAT-based assessment effectively helps students. Lecturers provide feedback for the assessment, students can identify the learning goals yet mastered, assessment not only the product but also the process, assessing all aspects of learning (authentic). Transparent and objective assessment make students do not feel disadvantaged. The application of diagnostic tests provides an overview to the teachers about the difficulties that still rose by students to achieve the learning goals. Oriented learning outcomes should ideally use the assessment that can give a continuous process and performance.

The research data shows that collaborative learning with $\mathrm{Gl}$ models and EAOAT-based assessment give a positive impact on the learning goals. The average final grades of student's is 79.2 , the average score of students' satisfaction is 92.5, expert lecturers assessment scores 95.8. From self assessment showed that students understand lecture material and the interest in the teaching profession was increased after the lecture.

\section{ACKNOWLEDGMENTS}

The acknowledgment delivered by the author to Board of Academic Development, Islamic University of Indonesia for funding this research through teaching grants odd semester 2016/2017. Thanks to Prof. Dr. Kamisah Osman from National University of Malaysia on the willingness to be Expert Lecturer during the study, Dr. Das Salirawati from Yogyakarta State University on the willingness of validating research instruments.

\section{REFERENCES}

1. S. S. Seferoglu, in: Proceeding of International Conference on Education (ICE, Sanfrancisco, 2005) pp. 709-716.

2. B. Akyol, EJER, 65, 19-35 (2016).

3. J. L. Nzilano, AJOTE, 3, 1, 1-21 (2013).

4. R. Smit, JERO, 6, 2, 21-43 (2014).

5. N. O. Akcay and K. Doymus, J. Educ. Sci. Res. 2, 1, 109-123 (2012).

6. S. M. H. Hosseini, Int. J. Inst. 7, 1, 177-188 (2014).

7. M. F. Tsoi, N. K. Goh, and L. S. Chia, APFSLT. 5, 1, 1-12 (2004).

8. Slavin, and E. Robert, Cooperative Learning: theory, research and practice (Allymand Bacon, London, 2005). 
9. A. Pitoyo, H. J. Waluyo, S. Suwandi, and Andayani, J. Educ. Prac. 5, 1, 21-29 (2014).

10.S. H. Parinduri, M. Sirait, and R. A. Sani, IOSR-JRME, 7, 4, 49-54 (2017). 